\title{
Reliability of routine hospital data on poisoning as measures of deliberate self poisoning in adolescents
}

\author{
C Sellar, M J Goldacre, K Hawton
}

\begin{abstract}
Study objective-The aim was to assess the extent to which routinely collected data on poisoning in adolescents reflected deliberate self poisoning and, in doing so, to assess the accuracy of the diagnostic information on poisoning in the routine hospital abstracts which form the joint data base of Hospital Activity Analysis and the Oxford Record Linkage Study (ORLS).

Design-A comparison was made (a) of all eligible ORLS records during the study period with an independent source of records; and (b) of a random sample of records from an independent source with ORLS.
\end{abstract}

Setting-Records of patients admitted to the John Radcliffe Hospital in Oxford were used.

Subjects-These were (a) patients aged 10-20 years between 1980 and 1985 with a diagnosis of poisoning by drugs and medicaments in ORLS; (b) a random sample of 500 patients selected from the self harm monitoring files at the hospital (12 patients were not eligible for inclusion in ORLS and were therefore excluded from the rest of the study).

Measurements and main results-The recorded diagnosis was compared on the records selected from the two files. Of the 1123 events of poisoning identified in ORLS, $1081(96.3 \%)$ were correctly coded as poisoning and $1065(95 \%)$ of these were deliberate self poisoning. Of the 488 cases from the monitoring files, $467(95.7 \%)$ of all cases had a correct diagnosis of injury or poisoning on the ORLS file. Of the 453 poisoning cases $436(96 \cdot 2 \%)$ were correctly recorded in ORLS.

Conclusions-Deliberate self poisoning in adolescents can be identified through routinely collected hospital statistics. A very high percentage of the diagnostic information on poisoning in ORLS files is correctly recorded.

University Unit of
Clinical
Epidemiology, Oxford
Regional Health
Authority, Old Road,
Headington, Oxford
OX3 7LF, United
Kingdom
C Sellar
M J Goldacre
Department of
Psychiatry, University
of Oxford, Oxford
K Hawton

K Hawton

Correspondence to: Dr Sellar

Accepted for publication March 1990 with therapeutic agents were coded under the ICD at N960-N979 as "adverse effects of medicinal agents". During the 1980 s, in the Ninth Revision of the ICD, such admissions were coded as "poisoning by drugs and medicaments" (960977). These codes do, however, also include overdoses of substances taken in error. The $E$ codes in ICD8 and the supplementary classification in ICD9 can be used to record the circumstances of an injury or poisoning but, quite commonly, these classifications have been recorded too inconsistently ${ }^{4}$ to be used to identify self poisoning in routinely collected hospital statistics.

Data held by the Oxford Record Linkage Study include data collected for Hospital Activity Analysis by the Oxford Region. In the course of a study of self poisoning in adolescents, we have compared routine hospital data from the Oxford Record Linkage Study with data collected independently in the Oxford research centre's monitoring system for self poisoning, which is maintained by the University Department of Psychiatry. Our objectives were, firstly, to assess the extent to which routinely collected data on poisoning in this age group reflected deliberate self poisoning; and, secondly, in doing so, to assess the accuracy of the diagnostic information on poisoning in the Oxford Record Linkage Study and the Hospital Activity Analysis.

\section{Methods}

The Oxford Record Linkage Study was used to identify all admissions to the John Radcliffe Hospital in Oxford for people aged 10 to 20 years with a main discharge diagnosis of poisoning by drugs and medicaments (ICD 960 to 977) in the years 1980 to 1985 . For each of these discharges, the record of self harm patients maintained by the monitoring service of the hospital was searched in order to determine if the episode had been identified as one of deliberate self poisoning.

A random sample of 500 records for people aged 10 to 20 years, who had a hospital admission between 1980 and 1985 for self harm (ie, deliberate self poisoning, deliberate self injury, or both together), was drawn from the records of the monitoring service. For each of these patients, the equivalent hospital discharge record was sought in the Oxford Record Linkage Study files.

Information contained in the Oxford Record Linkage Study files and in the records of the monitoring files was compared. Where discrepancies were found, the hospital case notes were used to determine which source contained the correct information. 


\section{Results}

CASES IDENTIFIED FROM THE OXFORD RECORD LINKAGE STUDY FILES

There were 1123 events of poisoning identified from the Oxford Record Linkage Study files. Of these, $1081(96.3 \%)$ were correctly coded as an episode of poisoning by drugs and medicaments (table I); $1065(95 \%)$ were deliberate self poisoning; $27(2.4 \%)$ were drug related events which should have been coded under other drug related ICD headings; $8(0.7 \%)$ of the episodes were miscoded with no mention of drugs in the hospital case notes. For five discharges it was not possible to trace a hospital record and two cases were duplicate records. (There were 12 additional cases identified from the Oxford Record Linkage Study files with poisoning as the second or subsequent diagnosis on the hospital record. Only four of these proved to be deliberate self poisoning.)

Table I Events of poisoning identified from Oxford Record Linkage Study files

\begin{tabular}{|c|c|c|}
\hline & Number & $(\%)$ \\
\hline $\begin{array}{l}\text { Correctly coded } \\
\text { Deliberate self poisoning }(n=1065) \\
\text { Accidental poisoning }(n=16)\end{array}$ & 1081 & $(96 \cdot 3)$ \\
\hline $\begin{array}{l}\text { Miscoded } \\
\text { Drugs for "kicks" (n=23) } \\
\text { Adverse effect of drugs in therapeutic use }(n=4) \\
\text { Overdose of alcohol }(n=4) \\
\text { No mention of drugs }(n=4)\end{array}$ & 35 & $(3 \cdot 1)$ \\
\hline $\begin{array}{l}\text { Hospital record not found } \\
\text { Duplicate records }\end{array}$ & $\begin{array}{l}5 \\
2\end{array}$ & $\begin{array}{l}(0 \cdot 4) \\
(0 \cdot 2)\end{array}$ \\
\hline Total & 1123 & $(100 \cdot 0)$ \\
\hline
\end{tabular}

CASES IDENTIFIED FROM THE MONITORING SERVICE The monitoring service includes all cases of self harm and therefore includes self injury as well as self poisoning. However, the sample of 500 cases of self harm from the monitoring service were predominantly cases of self poisoning: 463 records were for self poisoning alone; 18 were both self poisoning and self injury; and the remaining 19 were self injury alone. Four of the 500 patients proved to be outside the age range of the study and eight had not in fact been admitted to hospital. These are therefore-excluded from further consideration (table Ii).

For 467 of the remaining 488 cases $(95.7 \%$, 95\% confidence interval: $94.4 \%-97 \cdot 1 \%$ ) there was a hospital record on the Oxford Record Linkage Study file with a main diagnosis of injury or poisoning (ICD codes 800-989).

Seven of the cases on the Oxford Record Linkage Study files had no diagnostic information. In 13 cases the main diagnosis

Table II Events of self harm identified from monitoring files

\begin{tabular}{|c|c|c|c|c|}
\hline \multirow[b]{3}{*}{$\begin{array}{l}\text { Diagnosis correct } \\
\text { Diagnosis not made } \\
\text { Diagnosis different } \\
\text { Other error } \\
\text { Subtotal }\end{array}$} & \multicolumn{3}{|c|}{ Self harm type } & \multirow[b]{2}{*}{ Total } \\
\hline & Poisoning & Injury & Both & \\
\hline & $\begin{array}{rc}436 & (96 \cdot 2)^{b} \\
5 & (1 \cdot 1) \\
11 & (2 \cdot 4) \\
1 & (0 \cdot 2) \\
453 & (100 \cdot 0)\end{array}$ & $\begin{array}{rr}15 & (88 \cdot 2) \\
1 & (5 \cdot 9) \\
1 & (5 \cdot 9) \\
0 & \\
17 & (100 \cdot 0)\end{array}$ & $\begin{array}{rr}16 & (88 \cdot 9) \\
1 & (5 \cdot 6) \\
1 & (5 \cdot 6) \\
0 & \\
18 & (100 \cdot 0)\end{array}$ & $\begin{array}{rc}467 & (95.7) \\
7 & (1.4) \\
13 & (2 \cdot 7) \\
1 & (0.2) \\
488 & (100.00)\end{array}$ \\
\hline $\begin{array}{l}\text { Outside age range } \\
\text { Not admitted }\end{array}$ & $\begin{array}{l}4 \\
6\end{array}$ & $\begin{array}{l}0 \\
2\end{array}$ & $\begin{array}{l}0 \\
0\end{array}$ & $\begin{array}{l}4 \\
8\end{array}$ \\
\hline Total & 463 & 19 & 18 & 500 \\
\hline
\end{tabular}

Main diagnosis of poisoning (960-989) or injury (800-959)

$b$ Values in parentheses are percentages recorded included no information about an injury or poisoning episode. The hospital case notes for all but three of these cases (whose notes were not accessible) confirmed that the admission had been for an overdose or possible suicide attempt. In five cases the main diagnosis recorded was from Chapter V of the ICD, Mental Disorders, rather than that of the self poisoning.

In total, $21(4.3 \%)$ of the 488 self harm cases identified from the monitoring file did not have an accurate record on the Oxford Record Linkage Study file with a main diagnosis of injury or poisoning. The 21 cases comprised 17 self poisoning cases, two self injury cases, and two of both injury and poisoning. (One of these cases had a correctly coded second diagnosis of poisoning.)

In 16 cases where both self injury and self poisoning were reported on the monitoring file, and there was a matching hospital record, $13 \mathrm{had}$ poisoning as the main condition in the hospital record and three had injury as the main condition. In five of the 16 cases, poisoning and injury were both recorded in the diagnostic information on the hospital record.

E codes were recorded on 447 of the 467 cases where the main diagnosis was poisoning or injury. In the 20 cases where no external cause had been recorded, 14 were records with a main diagnosis of injury. This is a significantly greater proportion of injury than poisoning cases $\left(\chi_{1}^{2}=8.0, p<0.01\right)$. Ninety one $(19.5 \%)$ of the $E$ codes indicated that the cause of the poisoning or injury was "suicide or self inflicted" harm. These codes were rarely used before 1984 (see Discussion, below). The majority of cases $(n=348)$ were recorded under "Injury undetermined whether accidentally or purposely inflicted". Eight of the cases were recorded as accidental injury or poisoning.

There were some minor differences between the two files in the recording of specific substances used in self poisoning. For example, in 33 cases the main diagnosis recorded on the Oxford Record Linkage Study file was poisoning by unspecified drugs and medicaments, while the monitoring file had information about the type of substance ingested. There was only one case where the rìverse of this was true. In a further 30 cases the substances recorded on the two files were different, although 18 of these cases were the same to the level of three digits on the ICD code.

\section{Discussion}

The finding that $96.3 \%$ of the poisoning episodes in the Hospital Activity Analysis and the Oxford Record Linkage Study, and $95.7 \%$ of the self harm episodes in the monitoring service records, were coded correctly is encouraging when compared with the results of a study of self poisoning which used Scottish Hospital morbidity data. ${ }^{5}$ The errors had arisen in the Scottish data because commonly a psychiatric disorder was entered and the primary condition of poisoning was omitted. This was only a problem in five cases $(1 \%)$ in this study.

The use of the $E$ code as a record of deliberate self poisoning in Oxford requires some clarification. Although the category "undetermined whether accidentally or purposely inflicted" is "for use when it is stated 
that an investigation by a medical or legal authority has not determined whether the injuries are accidental, suicidal or homicidal", coding clerks in Oxford have in the past used this code in preference to "suicide" in cases where the hospital record indicates an overdose. In the latter years of the study this problem was overcome with the guidance that "overdose" should imply "self administered" for adults and be coded as deliberate self poisoning. Using this knowledge, only 12 of the 436 cases correctly recorded as poisoning were not recorded as deliberate poisoning; for six the $\mathrm{E}$ code was missing, and six were recorded as accidental poisoning.

Unlike self poisoning, self injury cases cannot be identified by the main condition alone because there are of course many external causes of injury other than deliberate self harm. Thus the high proportion of injury cases with an $\mathrm{E}$ code not recorded means that it is not possible to monitor accurately cases of deliberate self injury using hospital records.

Several papers have reported on the poor quality of diagnostic information in Hospital Activity Analysis for particular conditions. ${ }^{6-11}$ In general, these papers seem to have been by products of attempts to use the Hospital Activity Analysis for more substantive studies of the clinical conditions themselves. It is conceivable that there is some "submission bias" and/or "publishing bias" in the published reports, namely that findings of poor quality data are more striking and worthy of reporting than when the data used are found to be acceptable. Experience using diagnostic data in Oxford suggests that, while one cannot generalise, such data are commonly more trustworthy than is sometimes assumed.

The main aim of this study, undertaken in conjunction with our studies on the epidemiology of self poisoning, 21213 was to determine the extent to which episodes coded as poisoning in the ICD in teenagers actually are episodes of deliberate self poisoning. Self poisoning is a major health care problem; it is one of the commonest causes of hospital admission in adolescents, accounting for approximately $4 \%$ of all admissions in people aged 12-20 years. Thus trends in this behaviour have considerable implications for the use of health resources. Among the adolescent poisonings in our study, 1065 of the 1081 cases correctly coded as poisoning $(98.5 \%)$ were deliberate self poisoning. Thus, providing cases are coded accurately, routine data on poisoning in this age group are a good proxy for self poisoning with or without the E code.

The Unit of Clinical Epidemiology is part of the University of Oxford, Department of Public Health and Primary Care, and it is funded by the Department of Health. The Oxford Record Linkage Study is funded by the Oxford Regional Health Authority. The monitoring service for deliberate self poisoning and self injury has been maintained by grants from Oxford Regional Health Authority and the Medical Research Council. The authors would like to thank J Fagg, S Simkin, $H$ Simmons, L Gill, and G Bettley for their help with this study.

1 Platt S, Hawton K, Kreitman N, Fagg J, Foster J. Recent clinical and epidemiological trends in parasuicide in Edinburgh and Oxford: a tale of two cities. Psychol Med 1988; 18: 405-18.

2 Hawton K, Goldacre MJ. Hospital admission for adverse effects of medicinal agents (mainly self-poisoning) among adolescents in the Oxford Region. Br f Psychiatry 1982; 141: $166-70$.

3 Alderson MR. National trends in self-poisoning in women. Lancet 1985; i: 974-5.

4 Philipp R. Monitoring accidents and seat belt legislation HAA data and the use of $E$ codes in England and Wales. Community Med 1983; 5: 235-7.

5 Patel AR, Gray G, Lang GD, Baillie FG, Fleming L, Wilson LM. Scottish hospital morbidity data. 1. Errors in diagnostic returns. Health Bull 1976; 34: 215-20.

6 Martini CJ, Hughes AO, Patton VA. A study of the validity of the Hospital Activity Analysis information. Br ₹ Prev Soc Med 1976; 30: 180-6.

7 Stevenson $\mathrm{CH}$. What degree of error in Hospital Activity Analysis clinical data? Public Health 1982; 96: 137-40.

8 George AM, Maddocks GB. Accuracy of diagnostic content of Hospital Activity Analysis in infectious diseases. $\mathrm{Br} \mathrm{Med}$ 7 1979; i: 1332-4.

9 Harris AS. HAA for clinicians? A method for reducing errors in HAA diagnostic data. Public Health 1981; 95: 87-9.

10 Lockwood E. Accuracy of Scottish hospital morbidity data. Br F Prev Soc Med 1971; 25: 76-83.

11 Lennox B, Clarke JA, Drake F, Ewen SB. Incidence of salivary gland tumours in Scotland: accuracy of national records. Br Med F 1978; i: 687-9.

12 Goldacre MJ, Hawton K. Repetition of self-poisoning and subsequent death in adolescents who take overdoses. $\mathrm{Br} \mathcal{J}$ Psychiatry 1985; 146: 395-8.

13 Sellar C, Hawton K, Goldacre MJ. Self-poisoning in adokescentś: hospital admissions and deaths in the Oxford Region 1980-85. Br $\mathcal{F}$ Psychiatry 1990; 156: 866-70. 